\title{
AEROMAGNETIC MAP OF THE OTIS QUADRANGLE BERKSHIRE AND HAMPDEN COUNTIES, MASSACHUSETTS
}

By

G. R. Boynton, Peter Popenoe, and G. L. Zandle

\author{
GEOPHYSICAL INVESTIGATIONS \\ MAP GP-532
}

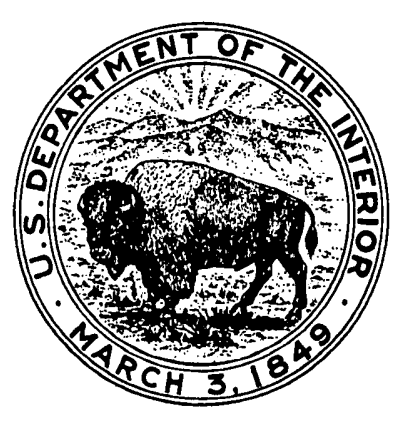

